\title{
¿Ha regresado Ulises?
}

La Odisea de Homero es uno de los poemas clásicos que ha tenido varias continuaciones, riquísimo arsenal al cual hubieron de acudir los ingenios de la literatura y cuya fortuna no puede amenguarse, pues que en el concepto de los críticos más agudos, el padre de la poesía, al trazar en cuadros de interés movido por la realidad y la imaginación, el arriesgado viaje de Odiseo o Ulises, escribió la primera novela de todos los tiempos. Se ha dicho que Virgilio, para el plan de su Encida, tuvo en cuenta el de los libros homéricos, por lo cual el héroe de su epopeya romana"es guerrero como Aquiles y viajero como Ulises y aún hay quienes han señalado la identidad de algunos cantos, sobre todo cuando Virgilio presenta la resistencia de Eneas, a prueba de la seducción de Dido, haciendo triunfar al hijo de Anquises, en nombre de la predestinación que había de llevarle, sorteador y en cierto modo estratega, al cumplimiento de su sino, alto y perdurable. No hay epopeya clásica que no se marque, siquiera con alguna remembranza uliseida y el mismo nombre del poema de Homero alcanza en breve una extensión metafórica que no se destruye, y desde entónces Odisea es el viaje difícil, la perpetua aventura, el errar impelido por los vientos adversos y es también, casi siempre, el regresar, el volver, figurando la columna humosa de la chimenea del hogar 
y las playas fieles del regazo de Penélope. $Y$ he aquí como lo pictóricamente objetivo de Homero se convierte en subjetivo y se habla de la Odisea interior, del viajero íntimo que zarja un día en el barco de la inquietud, es agitado por el Eolo de la duda, escucha el capcioso canto de las sirenas y, a merced clel piélago que no le da reposo, se afina en el descubrimiento y en la argucia, para encontrar la estela milagrosa del retorno. Uno de los poetas ecuatorianos de más fecunda voluntad, Numa Pompilio Llona, escribió La Odisea del Alma, siguiendo ese periplo de la brújula interna y haciéndose el Ulises propio de la borrasca espiritual y la Itaca perdida.

Camoens en su Los Lusiadas es coincidencialmente homérico, encontradamente virgiliano, uliseida diríamos mejor. Los navegantes del poeta portugués que no van en son de guerra, sino que se adornan con la promesa colónida de descubrir un nuevo país, sufren, como los compañeros de Ulises, las acechanzas del temporal y son recibidos asimismo por las seducciones que suelen asaltar al marino en la tierra firme o en la isla descansadora. Cuando la flota de Vasco de Gama llega al cabo del Buena Esperanza, irrumpe de pronto la aparición de un monstruo mitológico que es el vigilante del océano. Con él están las tempestades y los truenos y su advertencia no logra detener a los expedicionarios. Es, acaso, un símil del Eolo de La Odisea o en él se condensan, más bien, los poderes terroríficos del mar, pues no se ha dicho que consiguiese calmar a la ola amenazante, como Neptuno con el anclaje de su tridente.

Otro elemento mítico de Los Lusíadas, emparenta de nuevo a la epopeya portuguesa con el pocma de Homero: aquella isla que brota en son de oasis para la fatiga del mar desértico y que se ofrece blanda, tibia, constelada de mujeres, a Vasco de Gama y a los suyos. Venus dirige la partida flechadora para que las ninfas seduzcan a los marinos lusitanos y el Vasco, en medio de la fiesta que se enciende ardo- 
rosa, es conducido por la más bella de todas a una colina paradisíaca. $\mathrm{Y}$ así como en Homero y Virgilio, la calma de la tempestad se hace de modo providencial y el mismo de Gama se declara viajero más lejano que Ulises y Eneas.

No ha sido menos atractiva La Odisca para quienes quisieron exprimir de su deleitosa relación el sabor de la máxima, el gusto reflexivo, el ápice de la advertencia. Muy sabido es que Ulises representa la prudencia y la sagacidad y que en su hijo Telémaco hay la fiel proporción de un sentimiento filial y de una herencia de mesuras, destinada no obstante a otra erranza uliseida, la franca actitud del estudiante a quien dirige y aconseja Mentor, que es la misma diosa Minerva, en facha de Maestro. De la misma cantera homérica extrajo Fenelón la que llamaríamos sabiduría de La Odisea, para la enseñanza del Duque de Borgoña, y he aquí como brota la didáctica del libro amable y regresa Telémaco, trasluciendo las luces de Odiseo en su frente que se aclara con el horizonte del viaje.

\section{Biblioteca de Letras}

Pero lleguemos ya a la brevísima contemplación del Ulises moderno, del difícil Ulises de James Joyce, acerca del cual conocemos los estudios de Marichalar, de Manach, algunos párrafos del de Gilbert y el de Luis Alberto Sánchez en su "Panorama de la Literatura Actual". No se trata, ni lejanamente, de una continuación del tema homérico, pero en su complicada matemática se disponen, simbólicamente, los pasos de una Odisea subjetiva, objetivizada sólo hasta el punto de que los hechos sirvan para que la tortura del monólogo interior marque las etapas de un viaje breve pero intenso, señale el momento de partir e indique la hora del regreso. La disposición uliseana ha de ser apreciada en símiles demasiado sutiles y estimándose en la marcha de las simpatías y diferencias, nos ayudará a considerar como los personajes 
joycianos, coinciden con los del viejo Homero, siendo en realidad diferentes. Pero no perderemos de vista el caso de que Joyce, profundamente homerista, ha mecido muchas de sus angustias en las páginas del ciego de Chíos, identificándose con las figuras de La Odisea y que se ha propuesto la de un nuevo Ulises, parecido y diverso, arriesgado viajero como el de antaño, regresador también, actuante en un campo que se tiende más bien para dentro y en el cual las sirenas son pecadoras y el derrumbe se marca con un dejo de ansiedad. "Ulises-ha dicho Gilbert-es una obra esencialmente clásica por su espíritu, compuesta y ejecutada de acuerdo con las reglas y el plan de una precisión casi científica" y aún cuando allí no aparezcan ni Ulises, ni Telémaco, ni Mentor, ni Penélope, el lector avezado los descubre en Leopoldo Bloom, en Esteban Dédalo, en Buck Mulligan y en Marion Bloom. En un día casi entero, desde las horas de la mañana hasta la medianoche, el Ulises de Joyce se desparrama en la travesía cotidiana, vale decir en la odisea vulgar, llena de obstante de las pequeñas grandes aventuras que ofrece la vida y que sin el movimiento de lo extraordinario se riegan nervios adentro y forman esas Caribdis que todos llevamos alguna vez, remolino interior, tan tormentoso acaso como el que en aguas mediterráneas pusiera zozobra urgente en la travesía de Ulises. ¿Qué hace Leopoldo Bloom? Salir de su casa, de su Itaca intranquila, dejando a Marion Bloom, a su Penélope, si queremos buscar las comparaciones para establecer un parelelismo que siempre resultará difícil como la obra de Joyce, y claro está, sobre todo imperfecto. Dédalo es semejante a Telémaco en la inquietud de la búsqueda y $\mathrm{Mu}$ lligan se compararía trabajosamente con Mentor, en su actitud de enseñanza, aun cuando ésta sea sonriente y se exprima de la experiencia exterior del mundo, sin afirmadas teorías ni postulados éticos. Bloom es sensual, judío, traficante, y aquí la desviación de su personaje con respecto del héroe troyano que la da nombre, se marcará definitivamente, 
para que pensemos en la imposibilidad de identificarlos. Leopoldo Bloom recorre diversos lugares en un viaje que logrará desarrollar el trascendentalismo de lo intrascendente. Va a una iglesia, sin pensamicnto religioso alguno; asiste a los funerales de un amigo; visita la redacción de un periódico; permanece por algunos momentos en una biblioteca en donde discurre acerca de temas shakespereanos; penetra en un bar; concurre a una cita con Gerty Mac Dowel; presencia un caso en una maternidad; en compañía de Dédalo se complica lucgo en una ficsta bulliciosa y, por fin, regresa a su casa en la madrugada, cuando los diálogos incesantes han removiclo la explicación torturada de la aventura. ¿Pero será este, en verdad, un tema clásico? Hemos de convenir con los críticos de Joyce en que la simbología de La Odisea se cumple en este libro, por más que las figuras of rezcan en muchas veces, el contraste. No hay allí la tempestad homérica, pero los exegetas joycianos han querido referirse a los equivalentes. Cuando Bloom asiste a la redacción de un periódico es el mediodía, correspondiente al episodio de Eolo. Esteban Bloom estaba, pues, frente a los ödres de la publicidad, repletos de los vientos que viajan y pregonan. Fácil es, además, seguir a los comentaristas de Joyce en los pasos de su nuevo Ulises, señalados con los nombres de los cantos odiseos. En Los Lotófagos, por ejemplo, como en el poema homérico, si no llega a ese lugar en clonde se podía comer de una fruta que daba el olvido de la Patria, Bloom se pierde en su red de pensamientos eróticos para que Marion desaparezca casi del plano en el cual, para el Ulises griego, todo era sólo la concentración del regreso y la feliciclad doméstica. Las invectivas dublinesas figuran el canto de las sirenas, de gracia especiosa para el naufragio, y están representados los Cíclopes y Nausicaa y Circe e Itaca.... Solo que el Ulises de Troya resiste a la tentación y el de Joyce cede, y en éste la constante aventura, sin bañarse de milagro, busca sus interpretaciones en una crudeza dolorosa. Bloom y Dédlalo caen 
también en una isla como la de Circe y si allí se quedan, alentados por la orgía, a poco lanzan sus meditaciones rebotantes y sus paradojas ágiles para deshacer el encanto. ¿Se han convertido, acaso en fieras gruñonas, al probar del licor circense? ¿ El Ulises de Joyce fué prudente como el de Homero? Cuando los clos ebrios llegan a casa del cochero, parece aclararse la figuración de Emeo. Bloom cstá ya muy cerca de su Itaca. Es algo más de media noche y como en el despertar de Odiseo, 'Bloom se siente perdido en cierto modo. P'ero he aquí como la Marion de Leopoldo es una Contrapenélope, pues que si la homérica, para burlar a sus pretendientes recurría a la estratagema de la tela tejida y destejida, si era la fideliclad corporizada, la esperanza, la fortaleza, la de Joyce la teje en pocas horas y se la muestra provocativa, infiel, fácil, ligera. Esteban Bloom no ha regresado, como el estratega troyano, en traje de mendigo, para probarse una vez más y vencer, ayudado por los dioses. La mendicidad del judío joyceano es desoladamente total. No podrá perseguir a sus rivales para darles muerte. Le falta el arco potente. No queda destejida sino desgarrada la tela de su Penélope.

\section{"Jorge Puccinelli Converso»}

Con solo tener en cuenta el plan homérico, a Joyce que ya se había confesado antes en su devoción a Ulises, pudiera apreciársele como a uno de los escritores modernos que gustan de los temas clásicos y saben desarrollarlos con originalidad. Por otro lado, la obra, con toda su trama desconcertante, está fuerte, clásicamente estructurada y por eso hay quienes, con el trabajo que requiere la dedálica imaginación joyceana, se han detenido a considerar la matemática del libro, en la simbología uliseana, en la disposición del tiempo para el viaje de $B$ loom, en las edades de Esteban y Dédalo, en los juegos de palabras que conforman el estilo de 
este irlandés realista, clásico y moderno, y que vuelven particularmente difícil la traducción del Ulises, en opinión de los entendidos.

Así hubo de examinarse, en una obra clásica, La Diína Comedia, la matemática precisa y simbológica. El poema del Dante, escrito en tercetos es, según Cantú, uno y trino, en tres veces treinta y tres cantos, en cada uno de los cuales es casi igual el número de tercetos. "Tas distribuciones numéricas que principian en el primer verso ( $\mathrm{Nel} \mathrm{mezzo}$ ) le acompañan al través de los abismos, de los precipicios, de los cielos, coordinados siempre de nueve en nueve". El Dante conoció a Beatriz cuando ella tenía nueve años de edad y en la hora novena. Al tiempo de elogiarla "para mejor esconder su culto", debió hacerlo componiendo versos para sesenta damas florentinas y ningún otro número correspondió a Beatriz sino el noveno entre los de aquellas. El poeta cayo enfermo po nueve días cuando la obsesión de su amada platónico se le fijó en tenaces vigilias, al tiempo que las voces inesperadas le decían: "Un día tu morirás". "Ya estás mucrto". Todo esto de las mismas confesiones del Dante. cuyo terceto de la Comedia Divina es, porsí mismo, raíz del nueve.

(Jorge Puccinelli Converso»

Ulises clásico despertará otra vez a la lectura de Joyce y La Odisea estará presente cuando pensemos en el riesgo del viaje. Volverán, asimismo, siquiera las evocaciones nominales del poema, como en el "Ulises Criollo" de Vasconcelos, o encontraremos, otras 'veces, alguna figuración que nos recuerde remotamente el poema de Homero, como en el personaje de una de las novelas de Rudyard Kipling, aquella joven que para no casarse con el Comisario a quien sinceramente rechazaba, en el concurso de tiro propuesto 
por éste para premiar con un brazalete de diamantes a la certera tiradora, arrojó el arco fuera del blanco. ¿Diremos que regresa la prueba uliseida? Acaso no, por más que nos asalte la semejanza. Pero Kipling, clásico de nuestros tiempos, supo rememorar, acertando en la armonía humana.

Augusto Arias. 